\title{
Phenomenology and Perceptual Content
}

\author{
(Penultimate Version)
}

\section{Introduction}

In their seminal paper "The Intentionality of Phenomenology and the Phenomenology of Intentionality", Terence Horgan and John Tienson argue for the following claim, Phenomenal Intentionality: There is a kind of intentionality, pervasive in human mental life, that is constitutively determined by phenomenology alone. (Horgan and Tienson $2002,520)^{1}$

The phrase "constitutively determined" means that such intentionality "is not merely nomically determined; rather, intentional mental states have such intentional content by virtue of their

\footnotetext{
${ }^{1}$ Besides this paper, Horgan and Tienson have also made other contributions to the debates concerning phenomenal intentionality. The journal articles, book chapters, and book reviews that they have authored on this topic, sometimes singly, sometimes with other co-authors, include the following: Horgan, Tienson, and Graham 2003; Horgan, Tienson, and Graham 2004; Horgan, Tienson, and Graham 2006; Horgan and Kriegel 2007; Horgan and Kriegel 2008; Graham, Horgan, and Tienson 2009; Horgan 2011; Horgan and Graham 2012.

In these writings, one finds critical discussions of the externalist views that would separate phenomenology and intentionality, proposals to improve upon other philosophers' arguments for phenomenal intentionality, as well as treatments of various aspects of the phenomenology and epistemology of our experiences. To my knowledge, their other work does not contain discussions of the kinds of Husserlian themes that I take up in the present paper; nor have I found in it ideas that would obviously address my critical concerns.

To appreciate the dialectics of my paper, consider that I am not arguing that Horgan and Tienson's main claims are false, or that there is no conceivable way to improve their arguments, or that they have not succeeded in doing so, wherever one may look in their work. Instead, I am pointing out certain problems in "The Intentionality of Phenomenology and the Phenomenology of Intentionality", and proposing ways to address them by appeal to Husserlian ideas.
} 
phenomenology" (Ibid.). More specifically, Horgan and Tienson purport to show that phenomenal intentionality is a feature of our perceptual experiences and some propositional attitudes. Since my focus in this paper will be on perceptual experiences, I will generally not distinguish between Phenomenal Intentionality and the more specific idea that our perceptual experiences have phenomenal intentionality.

Horgan and Tienson's arguments crucially involve a phenomenal duplication thought experiment, inviting us to accept that, should there obtain a suitable pair of phenomenal duplicates, i.e., subjects whose experiences have exactly similar phenomenology, then these experiences would have the same intentional content. However, this argument is open to two lines of objection. First, in arguing for this determination claim, Horgan and Tienson are not sufficiently clear as to what kind of content it is that they take to be determined by, or to supervene on, phenomenal character. Preparatory to the phenomenal duplication argument in Section 3 of their paper, they do undertake, in Section 1, to provide an account of a kind of content that is "inseparable" from phenomenal character, but it seems to me that this account is problematic, undermining their determination claim. Second, Andrew Bailey and Bradley Richards object that, in order for Phenomenal Intentionality to follow, Horgan and Tienson would first have to establish the co-variation of phenomenology and intentional content, rather than just the uni-directional determination of intentional content by phenomenology. Moreover, even if they succeeded in establishing co-variation, Phenomenal Intentionality would still emerge as less plausible than its converse, representationalism, i.e., the view that intentionality is more basic than phenomenology, and that phenomenology depends on, or is reducible to, intentionality (Bailey and Richards 2014, 313-314). 
I will address these two challenges by appeal to Husserlian ideas. I will propose that we regard phenomenology, or what it is like to undergo a certain experience, as comprised of protophenomenology and phenomenology proper. By proto-phenomenology I mean non-intentional phenomenology, and I centrally have in mind visual and other sensations: what Edmund Husserl famously discusses as the sensuous matter (or hyle) of perceptual experiences. When I speak of phenomenology proper, I mean the complex, intentional phenomenology of common, everyday perceptual experience. I will, firstly, argue that a consideration of phenomenology proper renders it manifest that there is a kind of perceptual content that is inseparable from phenomenology and, indeed, determined by it. Such content is conceived in terms of fulfillment conditions, or what it takes to bring aspects of objects and scenes to different, and more complete, givenness, in the further course of the intentional experience. I will, secondly, argue that we can establish the primacy of phenomenology, relative to such fulfillment-conditional content, by tracing back the phenomenology proper and the intentional content to the pertinent proto-phenomenology, which functions to "constitute" it - the Husserlian term for the achievement of a kind of experiential unity, based on the functioning of visual and other sensations. To be clear, my main aim is not to determine what view Edmund Husserl may actually have held of the issues at hand, but to use aspects of a Husserlian view to facilitate progress in the phenomenal intentionality debate.

\section{2.}

The main body of Horgan and Tienson's paper is organized into five sections. In Section 1, they defend the Intentionality of Phenomenology (IOP) — we shall presently assess their support for this claim, as part of our main concern with Phenomenal Intentionality, 
The Intentionality of Phenomenology: Mental states of the sort commonly cited as paradigmatically phenomenal (e.g., sensory-experiential states such as color-experiences, itches, and smells) have intentional content that is inseparable from their phenomenal character. (Horgan and Tienson 2002, 520)

In Section 2, they proceed to argue for the Phenomenology of Intentionality (POI), The Phenomenology of Intentionality: Mental states of the sort commonly cited as paradigmatically intentional (e.g., cognitive states such as beliefs, and conative states such as desires), when conscious, have phenomenal character that is inseparable from their intentional content. (Ibid.)

Next, in Section 3, they offer an argument for Phenomenal Intentionality. They re-state that claim in such a way as to render it more explicitly interlocking with considerations central to their argument,

Let two creatures be phenomenal duplicates just in case each creature's total experience, throughout its existence, is phenomenally exactly similar to the other's. We can then state the Phenomenal Intentionality thesis this way:

There is a kind of intentional content, pervasive in human mental life, such that any two possible phenomenal duplicates have exactly similar intentional states vis-a-vis such content. (Ibid, 524)

In addition to invoking the idea of phenomenal duplication, the present formulation also differs from the above one in that it focuses specifically on intentional content, to be distinguished from intentional mode or attitude, viz., to argue that a kind of content is "determined and constituted wholly by phenomenology" (Ibid.). In Sections 4 and 5, Horgan and 
Tienson discuss certain upshots of Phenomenal Intentionality; we can set these discussions aside. $^{2}$

In sum, we can see that Horgan and Tienson's argument for Phenomenal Intentionality is preceded by discussions of IOP and POI. Indeed, they note that their argument for Phenomenal Intentionality, in Section 3, involves a "development" of the ideas that they have articulated in the first two sections, devoted to explicating and defending IOP and POI (Ibid.). We should therefore make sure that we are clear as to what IOP amounts to, and assess Horgan and Tienson's defense of it—while keeping in view POI as needed. As for the meaning of IOP, there appears to exist a consensus from which I see no reason to depart. Bailey and Richards take it to mean that "fixing the phenomenal fixes an important category of perceptual content," accepting the view for the argument's sake (Bailey and Richards 2014, 316). David Bourget and Angela Mendelovici provide a fundamentally similar reading, "We take IOP to say that each paradigmatic phenomenal property has an associated intentional content such that, necessarily, all instances of the property have this content" (Bourget and Mendelovici 2017, 9 of 34). ${ }^{3}$

${ }^{2}$ In section 4, they combine Phenomenal Intentionality with the widely accepted view that phenomenology is narrow, to argue that there obtains an important kind of content that is narrow. From this they conclude, in section 5, that strong externalist theories of intentionality are mistaken, that theories of reference should take into account the narrowness of phenomenal content (alongside what wide content there may be), and that the so-called hard problem of consciousness is, indeed, a very difficult problem.

${ }^{3}$ I regard it as uncontroversial that all these philosophers take Horgan and Tienson to be arguing for the claim that perceptual content supervenes upon phenomenal character, and that this is, indeed, the claim for which Horgan and Tienson need to argue, to make their intended contribution to the phenomenal intentionality debate. So, we take Horgan and Tienson to be arguing that there can be no difference in perceptual content without a difference in phenomenal character. Or, to express this in different but closely related terms, they are effectively arguing that 
With a view to this, it strikes me that, in their Section 1, Horgan and Tienson are not providing evidence for the supervenience claim IOP, and from reading their text it is not even very clear how they might be trying to support it. To begin, notice that, if they are, indeed, arguing that there is a kind of intentional content that is inseparable from phenomenal character, the heading "Intentionality of Phenomenology" may strike one as a bit of a misnomer, being suggestive of just the opposite inseparability claim. As it is, the name "Intentionality of

there is a surjective (i.e., onto) function from a (proper or improper) subset of the phenomenal characters to the set of the perceptual contents.

In order to establish this, Horgan and Tienson need to show that if a phenomenal character P (member of the domain), obtains in conjunction with perceptual content $\mathrm{C} 1$ (member of the co-domain), then it is not possible for $\mathrm{P}$ to obtain in conjunction with some other perceptual content $\mathrm{C} 2$ (member of the co-domain). They also need to show that the relevant function is surjective: it is not possible for a perceptual content to obtain apart from any phenomenal character. To paraphrase this, they need to show that perceptual content is inseparable from phenomenal character. For a similar example, to argue for the claim that the mental supervenes upon the physical, we would need to show that it is not possible for there to be something like the mental states of non-physical angels.

Notice, however, that Horgan and Tienson do not need to show that it is not possible for a phenomenal character to obtain without any perceptual content, because we have specified that the domain of the function can be a proper subset of the phenomenal characters. In other words, they do not need to show that phenomenal character is inseparable from perceptual content. It seems to me that in so construing supervenience, we have been faithful to the way philosophers use this notion. E.g., one could agree that the mental supervenes upon the physical, while accepting that there are many physical states and processes (even brain states and processes) for which there are no corresponding mental states or processes. So, while it is important for one to show that the phenomenal is inseparable (in our sense) from the intentional if she is arguing that the phenomenal supervenes on the intentional, it is not important for one to show this if she is arguing for the converse claim that the intentional supervenes upon the phenomenal. 
Phenomenology" is entirely consistent with the actual contents of their Section 1, in which they only defend the claim that phenomenal character cannot obtain separately from intentional content. I do not see them providing evidence for its converse. We see them invoking various cases to show that it is not possible to isolate aspects of phenomenal character. Far from amounting to raw, non-intentional phenomenal data, these aspects of phenomenal character can only occur as part of a larger, more complex phenomenology, which brings in its train intentionality. Thus, they argue, we could not isolate an experience of red from its spatial character. Also, the different sensuous features of, say, an apple will be unified, both intra- and inter-modally, into experience of an object that is located in space among other objects. Our pains, likewise, are experienced not as isolated raw pain feels but as situated, embodied pains. The aspect of embodiment, they contend, is also present in other experiences more generally, viz., insofar as various experiences necessarily involve the aspect of tactile or kinaesthetic experience of one's own body (Horgan and Tienson 2002, 521-522).

Horgan and Tienson are, emphatically, not subscribing to any kind of loosely conceived, all-encompassing contextualism or holism about the what-it-is-like. They do allow that "[f]or any experience involving a specific shade of red, one can abstract away from the total experience and focus on the distinctive what-it-is-like of that shade of red per se..." (Ibid., 521). Yet they maintain that "even considered in isolation from any total visual-experiential state, the what-it'slike of experiencing red is already intentional", insofar as we experience the redness "as a property of visually presented objects" (Ibid.). They defend, in Section 1, the view that we always experience certain aspects of phenomenal character as combined in such ways as to yield intentional experience - and they put forward fairly specific ideas as to which aspects of phenomenal character are needed to contribute towards this accomplishment. In other words, 
they defend the view that phenomenal character is inseparable from perceptual content, but they make no explicit argument to the effect that (a kind of) perceptual content is inseparable from phenomenal character.

Indeed, Horgan and Tienson do not, in their Section 1, seem to argue for anything stronger than what we might call indeterminant inseparability claims: they are not explicitly arguing that intentional content determines phenomenal character (or vice versa). For all that they are saying, the same sample of color or pain phenomenology could be part of different visual or nociceptive perceptual experiences, depending on its context within the larger experience. E.g., the dark red color-sensation could either be taken at face value, or it could form part of a perceptual experience of a light red color in dim lighting conditions. By contrast, their discussion of POI, in Section 2, does contain determination claims. In regard to certain paradigmatic propositional attitudes, they maintain that if we "[c]hange either the attitude-type (believing, desiring, wondering, hoping, etc.) or the particular intentional content, ... the phenomenal character thereby changes too," and that if we "[e]liminate the intentional state, ... the phenomenal character is thereby eliminated too" (Ibid., 522). This, of course, looks like a statement to the effect that the mode and content of these propositional attitudes is determined by their phenomenal character.

Concerning IOP, Horgan and Tienson might mean that if we accept that a kind of intentional content is inseparable from phenomenal character, then the step to accepting the determination claim IOP is, for some reason, entirely unproblematic. Or, they might mean that any remaining indeterminacy of content could be eliminated simply by specifying the phenomenal character in greater detail, or by contextualizing it within the total experience, in a more holistic fashion. 
My reaction to this is twofold. First, I am open to the possibility that Horgan and Tienson's arguments can be modified and improved, but I think making their case could be facilitated by a specification of what kind of content they have in mind, something they have not done in their discussion of IOP. Second, it seems to me that the idea of a kind of indeterminant inseparability could also be helpful to us, viz., if only we were given an account of a kind of perceptual content that we could accept as being inseparable from phenomenal character, preparatory to immersing ourselves in the details of the phenomenal duplication argument. But Horgan and Tienson seem merely to have shown that (certain paradigmatic) phenomenal character is inseparable from intentional content.

3.

Since our paper is concerned with the phenomenology of perceptual experiences, and we bring up POI only insofar as it is relevant to our purposes, let us skip the detail of Horgan and Tienson's Section 2, and turn to their defense of Phenomenal Intentionality, in Section 3 of their paper. As I have noted, their argument involves a thought experiment of phenomenal duplication, As argued in section 1, sensory-phenomenal states and processes have intentional content that is inseparable from their phenomenal character. These states present an apparent world full of apparent objects that apparently instantiate a wide range of properties and relations, and they present oneself as an apparently embodied agent within that apparent world. Since this kind of intentionality is inseparable from phenomenal character, your phenomenal duplicate will have an apparent world presented to it in exactly the same way. (Ibid., 524) 
As can be seen, Horgan and Tienson make a connection with their argument in Section 1, and then move very quickly to the determination claim contained in Phenomenal Intentionality. By itself, that move is too quick, since we do not yet really know what kind of intentionality they have in mind. However, Horgan and Tienson have a further argument for their determination claim, based on the idea that two phenomenal duplicates would necessarily have experiences with the same accuracy conditions, “[T]he sensory-phenomenal experience, by itself, determines conditions of accuracy: i.e., a class of ways the environment must be in order for the experience to be accurate.[16]" (Ibid.). E.g., if I am having an experience of a picture hanging crooked, then, for the experience to be accurate, there must, indeed, be a picture before me, hanging crooked. That the accuracy conditions are the same, for both phenomenally duplicated subjects, is attested to by the fact that they would go about checking their experiences for accuracy in the same ways, That these phenomenally identical experiences all have the same truth conditions is reflected in the fact that each of the experiences is subject in the same way to investigation as to whether it is accurate.[17] For example, you and your phenomenal duplicate each might have the experience of seeming to oneself to be testing one's perceptual experience for accuracy by making measurements or using a level. You and your phenomenal duplicate each might have the subsequent experience of seeming to oneself to discover that the picture merely appears to be crooked because of irregularities of the wall, or tricks of light. Or, you and your phenomenal duplicate might, in the course of seeming to oneself to be attempting to perform these tests, have the experience of seeming to discover that there actually is no picture - say, by seeming to oneself to discover that one has been looking at a clever holographic image cooked up to make it appear that there is a picture hanging on the wall.[18] (Ibid.) 
The structure of Horgan and Tienson's argument emerges as follows:

(1) The contents of perceptual experience are accuracy conditions.

(2) Phenomenal duplicates would go about investigating their experiences for accuracy in the same ways.

(3) If it is the case that phenomenal duplicates would go about investigating their experiences for accuracy in the same ways, then phenomenal character determines accuracy conditions.

(4) Phenomenal character determines accuracy conditions. Based on (2) and (3).

(5) Therefore, Phenomenal Intentionality. Based on (1) and (4).

Their endnotes 16,17 , and 18 also provide important clues regarding the philosophical context of their argument, as well as how they wish their points to be understood. Thus, citing Siewert 1998, they point the reader to Charles Siewert's arguments for (4). ${ }^{4}$ By way of

\footnotetext{
${ }^{4}$ Based on chapters 6 and 7 of Siewert's The Significance of Consciousness (Siewert 1998), here is a reconstruction of his argument:

(1) If we are assessable for accuracy in virtue of phenomenal features, then these phenomenal features are intentional features.

(2) We are, indeed, assessable for accuracy in virtue of phenomenal features.

(3) Therefore, these phenomenal features are intentional features.

Siewert supports (2) by arguing that perceptual experiences and beliefs have phenomenal features which render the subject assessable for accuracy without that feature's needing to be interpreted. He does not give a positive account of "in virtue of", or provide a definition of "interpretation" in general terms. In view of this, it might be suggested that, while we do not interpret the phenomenal character of perceptual experiences in the same way as we interpret, say, written text, assessing phenomenal features for accuracy, nevertheless, involves a kind of interpretation, viz., insofar as we interpret phenomenal character, as such, in accuracy-conditional terms. Siewert
} 
clarification, they also note that in appealing to ways of investigating experiences for accuracy, they by no means wish to construe accuracy (or truth) in terms of such avenues of investigation. Their view is not a brand of verificationism, and they accept that first-person tests for accuracy cannot provide a guarantee of accuracy.

This, as far as I can tell, is Horgan and Tienson's argument for Phenomenal Intentionality, regarding perceptual experiences. Phenomenal Intentionality is obtained by combining (1) and (4), and (4) is supported by (2) and (3). The argument appears to be focused on the idea that phenomenal character determines a kind of intentional content, rather than on the supplementary point that it does, indeed, do so "constitutively."

But this argument does not succeed, because premise (3) can be challenged. While Horgan and Tienson have argued that phenomenal duplicates use the same methods to investigate their experiences for accuracy, they have also cautioned us against conceiving of accuracy conditions in terms of these methods of investigation. For all we know, accuracy conditions could be un-coupled from these avenues of investigation and thus from phenomenal character, with a subject's conceivably having a perceptual experience with certain accuracy conditions, but no sense (or a deficient sense) of the possibilities of investigating it for accuracy.

How could accuracy conditions be thus un-coupled from the relevant avenues of firstpersonal investigation? It can be done by arguing that certain other, say, neurophysiological or behavioral, evidence is also relevant to discovering the accuracy conditions, that it can conflict with the first-personal evidence, and that it should, at least in some situations, be given precedence over it-e.g., when it seems to the subject as though she were seeing a spherical

\footnotetext{
certainly offers a rich and interesting discussion, but I do not believe that the considerations he offers will straightforwardly exempt Horgan and Tienson's views from criticisms.
} 
object, but a brain scan, let us imagine, only reveals activity in a cortical area for processing cubical shape. If this is possible, then we must allow that, say, in light of the neurophysiological evidence, one of the phenomenal duplicates can have a deficient sense of what it takes for his experiences to be accurate, and what it takes for him to investigate his experiences for accuracy, rendering (3) false, and depriving IOP and Phenomenal Intentionality of support. The supporter of phenomenal intentionality might counter this line of objection by asserting that he is talking about a specific kind of content, and his opponent, failing to see this, has invoked some other kind, though also accuracy-involving — but this would surely be a question-begging maneuver. To get past these problems, we need a notion of perceptual content that cannot be un-coupled from ways of first-personal investigation. What kind of content could it be?

4.

In a recent paper of theirs, Bailey and Richards argue that Phenomenal Intentionality will not amount to a credible view of perceptual experiences, unless we accept a co-variation of phenomenal character and intentional content. However, they also argue that even the acceptance of the co-variation ultimately will not help, because it will render representationalism the more plausible view of the relation between phenomenology and intentionality.

In Section 1 of their paper, Bailey and Richards provide an overview of Horgan and Tienson's argument, duly underscoring the importance of the phenomenal duplication thought experiment, including the role of the accuracy conditions and the significance of ways of investigating perceptual experiences for accuracy. At the end of that section, they outline their main criticisms, to be developed in more detail in the following sections of their paper. They claim that even if it is granted, for the sake of argument, that Horgan and Tienson's phenomenal 
duplication scenario suffices to show that perceptual phenomenology "fixes" perceptual content, this idea will be "too weak" to establish Phenomenal Intentionality. In Section 3, they present their arguments to the effect that it would need to be suitably strengthened; yet even so, they maintain, the argument for Phenomenal Intentionality would fail,

It is not enough, we have suggested, for the phenomenal to fix the phenomenal intentional; it must do so because of the nature of its phenomenality. That is, all and only phenomenal states of a certain class (e.g. red sensations) will fix a given phenomenal intentional content (e.g. perceiving redness). But this requires a converse relationship to that which HT emphasize: there should be no phenomenal intentional content of type Q without phenomenality of type $\mathrm{P}$; that is, any phenomenal change will correspond to a change in intentionality. Yet this is precisely the thesis of representationalism (sometimes called intentionalism): there is no phenomenal difference without an intentional difference. (Bailey and Richards 2014, 318)

Bailey and Richards are arguing that if the determination of intentionality by phenomenology is to be regarded as constitutive, then it must somehow be due to the intrinsic nature of the pertinent phenomenology. However, in that case, we would have to accept that the intentionality also determines the phenomenology, raising the question why Phenomenal Intentionality should be given preference over representationalism, In particular, what could support HT's assertion that the phenomenal grounds and "constitutes" the phenomenal intentional rather than, as the representationalist might hold, the other way around? HT — or any other proponent of the hypothesis of constitutive phenomenal intentionality — need an additional, independent argument for the priority of the phenomenal here, and it is not obvious from where it might come. (Ibid.) 
In making these criticisms, Bailey and Richards do not explicitly consider the significance of the idea that phenomenology determines accuracy conditions. Rather, they take IOP to mean that "fixing the phenomenal fixes an important category of perceptual content," and accept this view for the argument's sake (Ibid., 316). Somewhat confusingly, they also take themselves to have established, at the end of their paper, that the conjunction of IOP and Phenomenal Intentionality is false, insofar as "the intentionality of phenomenology can only be made plausible with acceptance of the equivalence relation between the relevant phenomenal and intentional states, but this undermines the phenomenal intentionality claim" (Ibid., 324). That is to say, they are not just saying that the conjunction is false because Phenomenal Intentionality is false, but seem, now, to have shifted from a weaker to a stronger reading of IOP, viz., from the claim that the phenomenal fixes the intentional, to the claim that the phenomenal constitutively fixes the intentional-seeming to collapse IOP into Phenomenal Intentionality, while also drawing the conclusion that IOP and Phenomenal Intentionality are mutually incompatible.

However, Bailey and Richards' main point remains un-adulterated by these equivocations, if such they are. Bailey and Richards have alleged that Horgan and Tienson's view is rightly interpreted as involving the idea that the determination relation between phenomenal character and intentional content is to do with the intrinsic nature of the relata, strengthening the one-way determination claim to co-variation, and argued that the co-variation claim is difficult to reconcile with Phenomenal Intentionality.

5.

In the following, I will address the above two objections to Horgan and Tienson's arguments, fixing what I take to be some flaws in their otherwise compelling defense of 
Phenomenal Intentionality. I will do so by appeal to a Husserlian account that enables us to establish that phenomenal character determines a peculiar kind of perceptual content, and that phenomenal character is prior to such perceptual content.

It will help us see that phenomenology determines intentionality if we focus on a certain aspect of phenomenology. Likewise, it will help us see that phenomenology is prior to intentionality, if we turn our attention to another aspect of phenomenology. These aspects are phenomenology proper and proto-phenomenology, already mentioned in my Introduction. Phenomenology proper is the complex, intentional phenomenology of our everyday experiences; proto-phenomenology is non-intentional phenomenology, e.g., of our visual and other sensations. Phenomenology proper is usually salient to us, while proto-phenomenology is usually more or less implicit, but can become saliently available to us if we closely attend to our experiences and reflectively investigate them.

In making these claims, I have in mind a particular kind of intentional content. To facilitate the introduction of this idea of content, I have previously highlighted the fact that Horgan and Tienson's phenomenal duplication argument relies on a certain widely accepted notion of perceptual content, viz., as accuracy conditions. Let us contrast this notion with another, which is based on the Husserlian idea of "fulfillment," i.e., a kind of experiential confirmation by virtue of the harmonious unfolding of the experience. To clarify this idea, consider the visual experience of an object, say, an apple. Provided that one accept that the apple as a whole is given in this experience, one would have to accept that the front side is experienced markedly differently from the back side. Let us call the experience of the front side "full" and the experience of the back side "empty." Now, if we turn the apple around to take a look at the back side, the back side is transitioned from empty to full givenness. We can call this this transition 
"fulfillment." Alternatively, we can also say that the back side comes to fulfillment. We can also say that the apple as a whole comes to a greater degree of fulfillment, insofar as I experience it from different perspectives and retain these perspectives as part of the ongoing experience. It is also part of the Husserlian view that the emptiness is conceived in terms of more or less implicit anticipations of different aspects of the apple, and fulfillments (disappointments) are achieved, with the anticipations being confirmed (disconfirmed). ${ }^{5}$

Insofar as this view yields an account of how objects and their properties are present to us in perceptual experience, we may say that there is a kind of perceptual content that amounts to fulfillment conditions, rather than accuracy conditions. ${ }^{6}$

We can now re-formulate Horgan and Tienson's phenomenal duplication argument in terms of such fulfillment-conditional content. We are not saying that since perceptual contents are accuracy conditions, and our phenomenal duplicates will necessarily have perceptual experiences with the same accuracy conditions (as evidenced by the fact that they will go about investigating their perceptual experiences for success or failure in the same ways), they will

\footnotetext{
${ }^{5}$ For an introduction to Husserl's view of perceptual experience, including a discussion of the significance of fullness and emptiness, see Bernet, Kern, and Marbach 1993, Ch. 4.

${ }^{6}$ On this view, do full and empty experiences of the same part of an object, e.g., the back side before and after I take a look, have the same content or not? Aspects of the content would be the same. Yet, insofar as the present notion of content captures our ongoing relationship with the object, it is important to say that, by virtue of the difference in the level of fullness alone, the entire contents would be different.

Why do I speak of contents as being (identical with) the accuracy or fulfillment conditions, and not as merely determining them? Since I am not aware of any important substantive reasons to prefer either locution to the other, I have chosen between them based on reasons of simplicity and style. I have no objection to the discussion's being re-cast in the alternative terms.
} 
therefore necessarily have perceptual experiences with the same content. Instead, we are now making an analogous argument, substituting fulfillment conditions for accuracy conditions. Since perceptual contents are fulfillment conditions, our argument goes, and the phenomenal duplicates will necessarily have perceptual experiences with the same fulfillment conditions (which is but another way of saying that they will go about investigating their perceptual experiences for success or failure in the same ways), they will necessarily have perceptual experiences with the same content. Notice that in switching to fulfillment-conditional content, we are, in effect, deepening Horgan and Tienson's emphasis on the significance of ways of investigating perceptual experiences for correctness or incorrectness - albeit in a manner that they might disapprove of. We have conceived of contents entirely in terms of such possible avenues of investigation, viz., yielding fulfillments or disappointments. Yet in the endnotes appended to their discussion of the phenomenal duplication thought experiment, Horgan and Tienson explicitly reject verificationism and kindred notions, as well as the idea that truth or accuracy could be conceptualized in terms of ways of testing, so that one's having performed all the relevant tests would amount to no less than a guarantee of truth or accuracy. They might be inclined to reject our ideas - even if we only propose to apply the fulfillment-based notion of content to perceptual experiences, not committing ourselves to any verificationist view of the content of propositional attitudes or the meaning of linguistic expressions.

But this view of content is well-suited to support the claim that phenomenal character determines perceptual content. Based, as it is, on the phenomenal contrast between fullness and emptiness, it is unquestionably inseparable from phenomenal character. In regard to the scope of the determination claim, it puts us in a position of enviable clarity as to what kind of content is involved. And, when we consider the modified phenomenal duplication argument, it 
straightforwardly succeeds, insofar as there is no longer a gap between the methods of investigation and the contents: the possible avenues of successful investigation are the fulfillment conditions, and the fulfillment conditions are the contents. This addresses the first of the two objections to Horgan and Tienson's argument for Phenomenal Intentionality.

Just to clarify, for this idea to work, we need not argue that fulfillment-conditional content is the only legitimate kind of perceptual content. Rather, the reader will need to accept that it is a legitimate kind of content, perhaps alongside accuracy-conditional content. And, lest someone worry that we have introduced the notion ad hoc, simply so that one side in the phenomenal intentionality dispute may prevail over the other, I maintain that our idea of content is also motivated by broader principled considerations. It importantly captures the phenomenological differences and dynamics between what is directly present and what is not directly present but also given in the experience, whether as more or less implicitly anticipated as coming up next, or as being available upon taking a closer look or making an exploratory effort. It, relatedly, brings to the fore the consideration that our experiences seem to be continually confirmed and reinforced (i.e., by fulfillments), or else disconfirmed or "shattered" (i.e., by disappointments), in the course of their unfolding, thus bearing on important questions concerning the extent of our epistemic rationality. ${ }^{7}$

Seizing upon the present acceptance of a kind of pluralism about content, someone might argue that the fulfillment-based and accuracy-based contents are, in fact, so closely related that a kind of problem emerges for our view. As the "empty" part of the experience points to other anticipated experiences of the apple's back side, will it not, by the same token, also point to the

\footnotetext{
${ }^{7}$ The present view promises to connect interestingly with Susanna Siegel's recent arguments for the rationality of perception (Siegel 2018).
} 
back side itself, as what would be seen in the fulfillment of these anticipations? If this is right, then it would seem that fulfillment-conditional content determines accuracy-conditional content. I agree that if we accept this determination claim, the present position will face difficulties. Namely, if phenomenal character determines fulfillment-conditional content, and fulfillmentconditional content determines accuracy-conditional content, then, by transitivity of supervenience, phenomenal character determines accuracy-conditional content. But if we accept this, why not simply argue that fulfillment conditions determine accuracy conditions, instead of also committing ourselves to the idea that there is a fulfillment-conditional content? The resultant argument seems seems to come close to being a mere re-statement of Horgan and Tienson's argument.

Yet, we have already objected to their argument, viz., at the end of our Section 3, and we can now re-cast our objection in terms of the idea that fulfillment conditions do not determine accuracy conditions. Consider that while accuracy is a kind of matching, or correspondence, between experience and reality, fulfillment is a kind of matching between the object as it is given to me in an experience, and the object as it is given to me in a subsequent experience.

These are markedly different ideas, insofar as the former, but not the latter, has recourse to anything like a conception of reality. Provided that we remain faithful to the perceiver's perspective, as the present approach purports to do, we are bound to accept that there can be perceivers who pursue fulfillments, and for whom fulfillments and disappointments make a difference-despite their not being cognitively equipped to conceive of their experiences as matching or mis-matching reality. Only when we have built a world out of such patterns of fulfillment, and risen to a level of considerable cognitive sophistication, can we have intentional experiences with fulfillment conditions which suffice to disclose reality — and enable us to 
conceive of anything like accuracy- or truth-conditions. Yet, even so, our sophistication can give rise to various competing views concerning the nature and individuation of contents, as reflected in the familiar current debates in the philosophy of mind and language, e.g., between proponents of internalist and externalist views. Such debates draw upon a variety of considerations, not only phenomenological ones. Yet, as phenomenologists, we cannot just shut them down in a sweeping fashion. Rather, by pursuing a kind of phenomenological approach, which I closely associate with the idea that the contents of our sensuous experiences are fulfillment conditions, we can hope to attain, not narrow certainties, but a kind of critical elucidation of different viewpoints. In sum, I believe that there is no warrant for claiming that the fulfillment-based contents determine the accuracy-based contents.

6.

We will now take up the second objection to Horgan and Tienson's argument for Phenomenal Intentionality, viz., Bailey and Richards' contention that they have failed to establish the primacy of the phenomenal over the intentional. Horgan and Tienson phrase the primacy idea in terms of the phenomenal character's "constitutive" role vis-à-vis intentional content: "intentional mental states have [their] intentional content by virtue of their phenomenology" (Ibid., 520). Husserl, it is well known, also uses the term "constitution," in what I believe to be a narrower sense, such that the Husserlian constitution amounts to a special case of constitution in Horgan and Tienson's sense. ${ }^{8}$ However, I will not attempt to argue for this

\footnotetext{
${ }^{8}$ Consult Part One of Tugendhat 1970 for an in-depth discussion of Husserl's account of the constitution of different kinds of objectivity in terms of what it takes to bring them to peculiar kinds of intuitive evidence, i.e., fulfillment.
} 
exegetic claim, but will, rather, just commit to consistently speaking of constitution in this way, as I aim to show that phenomenology (phenomenal character) constitutes perceptual content, conceived as fulfillment-conditional content.

As I see it, the Husserlian idea of constitution involves a relation between intentional content and the psychological resources that, roughly, go into our having an experience with this intentional content. Thanks to these psychological resources, we are able to have an intentional experience in which objects or states of affairs are revealed to us. We may say that, from a plurality of "constituents," a kind of unity has been produced. Yet constitution is, emphatically, not a relation between an item and its components. Thus, color sensations make a constitutive contribution towards our having a perceptual experience with certain color content, but the color sensations are not part of this content, much less the perceived color itself. I believe that this failure of parthood is mainly because constitution in the Husserlian sense produces entirely new realms and layers of sense (or meaning), such that to view the constituting resources as part of the constituted products, would likely amount to a kind of category mistake.

I propose to develop aspects of Horgan and Tienson's account by considering constitution, more specifically, as certain proto-phenomenological items' entering into "motivational" relations among themselves, yielding fulfillment-conditional content as product — for present purposes, the reader may take "motivation" just to mean mental causation. ${ }^{9}$

\footnotetext{
${ }^{9}$ A thorough treatment of Husserl's idea of motivation can be found in Rang 1973. Andrea Staiti takes issue with Bernhard Rang's interpretation, for appearing to contrast motivation with causation (Staiti 2010, 122). For an accessible recent discussion of motivation, which, moreover, brings to bear Husserlian views on the phenomenal intentionality debate, see Walsh 2017. Like the present author, Walsh invokes Husserlian ideas to argue for phenomenal intentionality, but our focal concerns and argumentative strategies are somewhat different. Walsh
} 
I will sketch briefly the role of such motivational relations in the "apprehension" (Auffassung) of the spatiality of objects, based on passages from Husserl's Thing and Space, a 1907 lecture series. We will see that, in Thing and Space, apprehension is conceived as the process in which kinesthetic sensations function to "motivate" or "animate" the visual sensations, so that the visual sensations can function to present aspects of the object, or shape properties more specifically. In this context, "motivation" or "animation" basically means that if series of visual sensations are accompanied by series of kinesthetic sensations, the perceiver expects that a certain continuation of the kinaesthetic series will be accompanied by a certain continuation of visual series. E.g., in an everyday setting, if I move in a certain direction and the object looms larger and larger, I expect, absent other motivations, that if I continue to move in this direction, the object will loom larger still.

I wish to emphasize that such visual and kinaesthetic sensations are not just one part of the constitutive input enabling us to experience of objects' shape properties, to be complemented by other items, perhaps of a more intellectual nature. Rather, we may, in a Husserlian vein, use a kind of hylomorphic language to emphasize that no additional constituents are needed, and to underscore the drastically different constitutive roles of the two kinds of sensations. In their constitutive functioning, the visual sensations are the hyle (or matter) and the kinaesthetic sensations the morphe (or form). ${ }^{10}$ Unlike the visual sensations, the kinaesthetic sensations $d o$

brings the notion of motivation center-stage, and discusses it in relation with the notion of horizon, drawing upon aspects of Husserl's later views. While I focus on Horgan and Tienson's account, Walsh engages in a polemic with authors such as David Woodruff Smith and Ronald McIntyre, as well as Katalin Farkas.

${ }^{10}$ For Husserl's contrasting between the sensuous hyle, and the noesis as the intentional morphe, see Husserl 1982, § 85. Husserl does, in fact, use the term "noesis" in two different senses. On the one hand, "noesis" 
not "adumbrate bodies or present them by way of projection. And yet without their cooperation there is no body there, no thing" (Husserl 1997, 136). To illustrate the different roles of the visual and kinaesthetic sensations, consider the following quotation, concerning visual images fa, $\mathrm{fb}, \mathrm{fc}$, and fd, perspectives of a square obtained by fixation of gaze on the corners a, b, c, and d (Husserl calls these images "pre-empirical figures."),

Phenomenologically, we find that in this continuous transition, fa "refers" [hinweist] to its continuous neighbors, and that therefore intentions penetrate the series fa to $\mathrm{fd}$ and are continually fulfilled in the elapsing of the series. We discover, founded in these moments, a thorough consciousness of unity. ... It is quite different with the series of the K's [kinaesthetic sensations]. They do not refer to each other; they elapse, but they are not bearers of intentions that penetrate them, intentions of the kind which the f's possess. That is, they are not traversed by a consciousness of unity... The consciousness of unity runs only through the f's, not partially through the K's partially through the f's. On the other hand, they are not joined as a mere conglomeration but rather in such a way

means the "animating" aspect of the experiencing process. On the other hand, it means both the "animating" aspect and the animated visual sensations, i.e., not the one aspect but the entire process. For example, the contrast between the noesis and the hyle is drawn ibid., 207, and the more inclusive notion of noesis is presented ibid., 233.

My present use of the hylomorphic language is inspired by Ulrich Claesges' explication, in a discussion of Thing and Space, of noesis in the narrower sense, "The authentic noesis of the consciousness of the phantom is the "kinesthesis," ... [ftn. 1], which, as noesis, underpins the general lawlikenesses of intentionality" ["Die eigentliche Noesis des Phantombewusstseins ist die "Kinästhese" ... [ftn. 1], die als Noesis den allgemeinen Gesetzlichkeiten der Intentionalität unterliegt.“] (Claesges 1964, p. 64). However, in reading this emphatic statement, it must be kept in mind that we cannot just identify the kinaesthetic sensations with the noesis or the apprehension. Rather, the former function as the latter. I will have more to say about this presently. 
that if $\mathrm{K} 0$ passes over into $\mathrm{K} 1$, fo passes over in expectation to f1, referring to

[hinweisend]—and being fulfilled in—each new phase. (Ibid., 152)

Thus, the f-series can be traversed by a consciousness of unity that is produced in a fusion of intention and fulfillment, but the K-series cannot. However, the K-series can be viewed as what provides the f-series with the unity. Husserl also adds that the K-series is a series of that which has the same "determination and form everywhere," the f-series, on the other hand, is a series of images that are "new everywhere" (Ibid., 155).

Given that the K-motivation makes such an important and distinctive contribution, it should not come as a surprise that Husserl closely associates such motivation with the apprehension of the thing, "Apprehensions of things and thingly nexuses are "webs of motivation:" they are built through and through from intentional rays, which with their sensecontent and their filled content, refer back and forth, and they let themselves be explicated in that the accomplishing subject can enter into these nexuses" (Husserl 1989, 236).

Let me be absolutely clear on one point. I am not identifying the kinaesthetic sensations with the apprehension, thereby either incorrectly intentionalizing the former or, just as incorrectly, de-intentionalizing the latter. Rather, the kinaeshetic sensations function to bring about the apprehension. How they do this is the central topic of Husserl 1997, Section IV, a discussion which provides ample textual evidence to the effect that this is, indeed, Husserl's position. ${ }^{11}$

Basically, the unifying role of the kinaesthetic sensations is due to their functioning to evoke certain visuo-kinaesthetic anticipations, which, insofar as they are fulfilled, evoke a

${ }^{11}$ For statements concerning the apprehensional role of kinaesthetic sensations, see especially Husserl $1997,136,144,147,157-159$. 
harmonious sense of unity. Here we have an embryonic version of the anticipation-fulfillment pattern that determines fulfillment-conditional content, which enables us to represent objects and their various aspects by pointing to different, more complete, and better givennesses of the object, beyond what is, strictly speaking, present to us, viz., the front side, from a certain point of view, under certain lighting conditions. ${ }^{12}$

According to our Husserlian view, the constitutive process, aspects of which we have just presented, is necessary and sufficient for there to be a perceptual experience. In the constitutive process, proto-phenomenology, e.g., the phenomenal character of the visual and kinaesthetic sensations, takes primacy over intentional content, as it functions to bring about a perceptual experience with a certain intentional content. ${ }^{13}$

${ }^{12}$ Ulrich Claesges, editor of the German, Husserliana edition of Thing and Space, captures it in a nutshell, "A res extensa is constituted by its transferability to its optimal appearance" ["Eine res extensa ist konstituiert durch ihre Überführbarkeit in ihre optimale Apparenz."] (Claesges 1964, 64). The study of constitution is the study of what it takes to bring the object, or some aspect of it, to fulfillment, or a kind of optimal appearance.

For a recent, comprehensive overview of Husserl's ideas concerning perceptual optimality, see Doyon 2018.

${ }^{13}$ What I call proto-phenomenology, Husserl has described as amounting to mere "dead matter", in the absence of an animating apprehension (Husserl 1997, 39-40). How does this square with my according the protophenomenology a central role in the present account? What I call proto-phenomenology is, indeed, dead matter in the sense that it does not yet present any object. E.g., we have color sensations, but we are not yet experiencing the colors of any perceived object. However, what matters to me is that even such non-intentional color sensations can be said to possess a phenomenal character: there is something it is like to have them. Husserl, to my knowledge, does not say anything that could be interpreted as a denial of this.

We have already seen that, in order for the dead matter to come alive, to acquire an animating significance, there needs to obtain a suitable organization and mutual functioning of the visual and kinaeshetic 
I will make some clarificatory remarks concerning the position we have reached, as well as addressing certain objections. First, it should be clear that our notion of fulfillment-conditional content is, indeed, needed to establish the primacy of the phenomenal as we have just done. The constitutive process is basically one of producing anticipations which realize fulfillment conditions - and also resolving them in fulfillments. This process yields content as conceived in fulfillment-conditional terms, and can be deemed as indispensable for the obtaining of such content, while its bearing on accuracy-conditional content is a considerably less straighforward matter.

Notice also that we can now address Bailey and Richards' specific issue with the covariation of the phenomenal and the intentional: they believe that co-variation must be accepted, but it will direct us to representationalism, rather than Phenomenal Intentionality. While we can agree that, in a way, the phenomenal and the intentional co-vary, we find the co-variation between visuo-kinaesthetic motivational complexes, on the one hand, and perceptual content, on the other. Yet, so that the processes of integration into the relevant kind of motivational complexes can take place, it seems that there must also be stray sensations that are not yet part of the motivational complexes. We allow for the possibility of such isolated or un-integrated sensations (possessed of a phenomenal character of their own), but do not presume to enter into further speculations about them. In taking this approach, we follow Husserl, according to whom "[the kinaesthetic sensations] play an essential role in the appearance of every external thing" (Husserl 1997, 136); and yet it must be kept in mind that "[they] lack an essential relation to the visual sensations; they are connected to them functionally but not essentially. The bond in the

sensations. Husserl's discussion on pp. 39-40 is early in the book (or in the lectures), and he is invoking apprehension without yet elucidating it in the ways that he does later in the text (Ibid., Section IV). 
case of functional unity is a bond of what is separable..." (Ibid., 143). But ultimately, our account of the motivational primacy of proto-phenomenology stands, irrespective of whether there are such stray sensations or not.

Yet, regarding our use of a Husserlian idea of constitution in establishing the "constitutive" primacy of the phenomenal, it might be objected that Horgan and Tienson's notion of constitution is further apart from the Husserlian notion than we have supposed, calling our approach into question. While Horgan and Tienson are talking about a relation between phenomenal character and intentional content, to which the latter owes its essence, are we not effectively saying that constitution is something that the perceiver does to objects? E.g., the perceiver "constitutes" an apple, as it were, by weaving a web of anticipations around it.

I cannot accept this rendition of our view. Horgan and Tienson argue that content depends on character for its nature, or essence, and the Husserlian view is a version of that idea. Thus, from the Husserlian perspective, we are talking about a dependence relation, one term of which is the aggregate of constitutive resources, and the other term can be variously regarded either as the intentional experience (in which the object is given to us), or as the object (as it is given to us, in the intentional experience).${ }^{14}$ Some aspects of the constitutive process are active,

14 The way I see it, there is a major mistake to be avoided here. The constituting-constituted relation, as it is understood here, is not a relation between the intentional act (i.e., intentional experience) and the object to which it is directed. As far as I know, my rendition of Husserl's view is correct and in line with other deep and thoughtful readings. For example, James Mensch regards the Husserlian account of constitution as development upon the Kantian idea of a synthesis of apprehension, which enables the object, viz., as a unity, a "one-in-many", an X that is distinct from the synthesized elements, to arise from a temporally dispersed multiplicity of intuitions (Mensch 2010, Ch. $1, \S 3)$. On Mensch's view, it is the peculiarly Husserlian approach to address this topic by invoking constitutive layers or strata (Ibid., Ch. $2, \S 1$ ). In the constitutive process, a subjective and objective side come apart. 
while others are passive. Furthermore, the constitutive process endows the intentional experience with its nature, or essence. Indeed, we must keep in mind that there are essences at different levels of generality. Although the Husserlian "eidetic" investigation deals in abstractions, this does not mean that we need to generalize away from the nuance and detail of our intentional experiences - a move which Horgan and Tienson might deplore. As far as I can see, the Husserlian idea of constitution is not altogether different from Horgan and Tienson's, except for being more specific, insofar as it involves the achievement of a kind of unity, out of a plurality of psychological resources.

Next, we can now also dispel a worry that may have arisen upon the reader's first introduction to the closely related ideas of phenomenology proper and fulfillment-conditional content. Namely, it may have seemed that, insofar as our whole idea of content depends on visual anticipations of various kinds, we may be inadvertently smuggling anticipatory content into our view, thus failing to establish the primacy of the phenomenal. But we have seen that, on the Husserlian view, the pattern of anticipation and fulfillment should not just be conceived in intentional terms, but is a wider-ranging feature of our conscious lives. We have seen it at work as visuo-kinaesthetic anticipations in the perception of shape, but on the Husserlian view it is a ubiquitous feature of the constitutive account. We perceive colors thanks to anticipations concerning their modulation in different lighting conditions, material things thanks to anticipations concerning their interactions with each other, tools and cultural objects in terms of

Consider that it only makes sense to speak about a perceptual experience when there is already a perceptual object. The perceptual experience cannot therefore be regarded as the constitutive origin of the object, but is, instead, co-constituted with it. 
anticipations concerning their uses and significance. ${ }^{15}$ There is a kind of constitutive hierarchy, and the anticipations bottom out with something like the motivational complexes of visual and kinaesthetic sensations that we have described. It could also be seen, insofar as I placed emphasis on the idea that these motivational complexes formed hylomorphic unities, that they do not, so to speak, require any third component—perhaps of a more intellectual nature and involving intentional content — to function as binding glue between the visual and kinaesthetic sensations.

There may be remaining critical concerns. With all our talk about a constitutive hierarchy, how exactly do we propose to account for the arising of intentional content out of a mix of non-intentional items? For example, how do we get "empty" intentionality from protophenomenology? Apparently even more challenging, how do we progress from the simpler cases of "empty" or "full" intentionality, to the complex case, where "empty" and "full" aspects are combined? Further, how is it that anticipations can attach to visual sensations and render them intentional, unless these anticipations are themselves already intentional?

There is an aspect of the Husserlian view that we have thus far not brought to the reader's attention. We will now appeal to it to address these concerns. Namely, on the present view, the very idea of objectivity is conceived in terms of a kind of orderly persistence in the flux of experience. ${ }^{16}$ Vis-à-vis the changeable flux of sensations, the constancy of the perceptual

${ }^{15}$ Regarding colors, see Husserl 1989, 46. Concerning material thinghood, see ibid., $§ 15$, especially $\S 15 \mathrm{c}$. For a discussion of Husserl's different notions of the Lifeworld, pertient to our topic of constitution, see Carr 1970, xl-xli.

${ }^{16}$ Of course, in order for the transcendence to emerge, the flux needs to be shot through with animating significance, giving rise to the relevant anticipations (with the concomitant emptinesses) and unity. We have already explained that the source of the animation is not to be sought outside the flow, but in the mutual functioning of series of kinaesthetic and visual sensations. 
properties, as well as the identity of the perceptual object, assert themselves by orderly persistence. In Husserlian terminology, therein consists their "transcendence" (Husserl 1997, p. 315). The Husserlian notion of transcendence contrasts sharply with the Kantian notion. For Kant, what is transcendent lies beyond possible experience: things in themselves, the Kantian Dinge an sich, are the transcendent things. In Husserl, on the other hand, the transcendence is achieved not beyond experience but within and in terms of experience.

On these terms, intentionality arises from the non-intentional precisely when a kind of orderly persistence emerges, or, if the reader prefers, when transcendence gains a foothold in the experiential flux. In our above block quotation, illustrating the constitutive interactions of series of visual and kinaesthetic sensations, we have a case of this, insofar as the two series are deemed to evoke a kind of rudimentary "empty" anticipation of more of the same, "interpreting" the present visual sensations, so to speak, and beginning to delineate a spatial feature of an object. Since objectivity arises precisely in such temporal integration, it is not correct to speak of any kind of "empty" or "full" intentionality as basic. Instead, in the basic case, the different phases of the experience, past, present, and future, combine and mutually illuminate one another, so that we can experience something in terms of fullness and emptiness. Regarding the intentionality of the anticipations, it could be said that while in the context of phenomenology proper, many percepual anticipations are already intentional in their own right, a consideration of protophenomenology nevertheless shows that their intentionality cannot precede the kind of primordial temporal integration which they facilitate. Relatedly, the most basic visuokinaesthetic anticipations are not conceived as something that the subject brings to a visual sensation. Rather, they arise and subside as a result of ongoing interactions between series of visual and kinaesthetic sensations. Also, this kind of constitution should not be conceived in 
compositional or reductionist terms. The constituted contents correlate with the constitutive inputs and processes, without being reducible to the latter. Our account does not purport to reduce the intentional to the non-intentional.

Finally, I would bring us back to where we started, viz., scrutinizing Section 1 of Horgan and Tienson's paper for arguments for IOP. Notice that much of what we have said about the Husserlian constitutive processes, including a mention of the hierarchical ordering of constitutive achievements, connects well with the phenomenological considerations offered by Horgan and Tienson, as they delineate the ways in which raw sensations are unified as part of perceptual experiences. With a view to that, it would not be out of place to reaffirm that, while taking a critical stance towards their arguments, and introducing certain Husserlian ideas to overcome their difficulties, we have, throughout, been on their side, working to un-tap the potential of their approach.

\section{Conclusion}

I have argued that there is a way of addressing what I take to be two important objections to Horgan and Tienson's argument for Phenomenal Intentionality, viz., by invoking Husserlian ideas, especially fulfillment and constitution. I have also complemented these ideas with a distinction between proto-phenomenology and phenomenology proper. A focus on phenomenology proper helped us see that phenomenology determines a kind of perceptual content, viz., fulfillment-conditional content. We then established the primacy of phenomenal character over fulfillment-conditional content by tracing the relations of motivational dependence between such content and proto-phenomenology, along the lines of the Husserlian account of constitution. 


\section{References}

Bailey, Andrew, and Bradley Richards. "Horgan and Tienson on Phenomenology and Intentionality." Philosophical Studies 167, no. 2 (2014): 313-326.

Bernet, Rudolf, Iso Kern, and Eduard Marbach. An Introduction to Husserlian Phenomenology. Evanston, Illinois: Northwestern University Press, 1993.

Carr, David. "Translator's Introduction." In The Crisis of European Sciences and Transcendental Phenomenology, by Edmund Husserl, xv-xliii. Evanston, IL: Northwestern University Press, 1970.

Claesges, Ulrich. Edmund Husserls Theorie der Raumkonstitution. Phaenomenologica. The Hague: Martinus Nijhoff, 1964.

Doyon, Maxime. "Husserl on Perceptual Optimality." Husserl Studies 34, no. 2 (2018): 171-189.

Graham, George, Terence Horgan, and John Tienson. "Phenomenology, Intentionality, and the Unity of the Mind." In The Oxford Handbook of Philosophy of Mind, by Brian McLaughlin, Ansgar Beckermann and Sven Walter (Ed-s). Oxford, UK: Clarendon Press, 2009.

Horgan, Terence. "Phenomenal Intentionality and the Evidential Role of Perceptual Experience: Comments on Jack Lyons, Perception and Basic Belief." Philosophical Studies 153, no. 3 (2011): 447-455.

Horgan, Terence, and George Graham. "Phenomenal Intentionality and Content Determinacy." In Prospects for Meaning, by George (Ed.) Schantz, 321-344. Berlin, Germany: De Gruyter, 2012.

Horgan, Terence, and John Tienson. "The Intentionality of Phenomenology and the Phenomenology of Intentionality." In Philosophy of Mind. Classical and Contemporary Readings, edited by David Chalmers, 520-533. New York: Oxford University Press, 2002.

Horgan, Terence, and Uriah Kriegel. "Phenomenal Epistemology: What Is Consciousness That We May Know It So Well?" Philosophical Issues 17, no. 1 (2007): 123-144.

Horgan, Terence, and Uriah Kriegel. "Phenomenal Intentionality Meets the Extended Mind." The Monist 91, no. 2 (2008): 353-380. 
Horgan, Terence, John Tienson, and George Graham. "Internal-World Skepticism and the SelfPresentational Nature of Phenomenal Consciousness." In Self-Representational Approaches to Consciousness, by Uriah Kriegel and Kenneth Williford (Ed-s), 42-61. Cambridge, MA: The MIT Press, 2006.

Horgan, Terence, John Tienson, and George Graham. "Phenomenal Intentionality and the Brain in a Vat." In The Externalist Challenge, by Richard Schantz (Ed.), 297-318. Berlin, Germany: De Gruyter, 2004.

Horgan, Terence, John Tienson, and George Graham. "The Phenomenology of First-Person Agency." In Physicalism and Mental Causation: The Metaphysics of Mind and Action, by Sven Walter and Heinz-Dieter Heckmann (Ed-s), 323-341. Thorverton, UK: Imprint Academic, 2003.

Husserl, Edmund. Ideas Pertaining to a Pure Phenomenology and to a Phenomenological Philosophy. First Book. Edmund Husserl Collected Works. Translated by F. Kersten. Vol. II. The Hague: Martinus Njihoff, 1982.

-. Ideas Pertaining to a Pure Phenomenology and to a Phenomenological Philosophy. Second Book. Edmund Husserl Collected Works. Translated by Richard Rojcewicz and Andre Schuwer. Vol. III. Dordrecht: Kluwer Academic Publishers, 1989.

-. Thing and Space. Lectures of 1907. Edmund Husserl Collected Works. Edited by Richard Rojcewicz. Translated by Richard Rojcewicz. Vol. VII. Dordrecht: Kluwer Academic Publishers, 1997.

Mensch, James R. Husserl's Account of Our Consciousness of Time. Milwaukee, WI: Marquette University Press, 2010.

Rang, Bernhard. Kausalität und Motivation. Phaenomenologica 53. The Hague, Netherlands: Martinus Nijhoff, 1973.

Siegel, Susanna The Rationality of Perception. Oxford, UK: Oxford University Press, 2018.

Siewert, Charles. The Significance of Consciousness. Princeton, NJ: Princeton University Press, 1998.

Staiti, Andrea Sebastiano. Geistigkeit, Leben und geschichtliche Welt in der Transzendentalphänomenologie Husserls. Studien zur Phänomenologie und praktischen Philosophie. Edited by Lore Hühn, Laszlo Tengelyi, Günter Zöller Hans-Helmuth Gander. Vol. Band 18. Würzburg, Germany: Ergon, 2010.

Tugendhat, Ernst. Der Wahrheitsbegriff bei Husserl und Heidegger. Berlin, Germany: Walter de Gruyter, 1970. 
Walsh, Philip, J. "Motivation and Horizon: Phenomenal Intentionality in Husserl." Grazer Philosophische Studien 94, no. 3 (2017): 410-435. 